\title{
Intraductal Breast Papilloma
}

National Cancer Institute

\section{Source}

National Cancer Institute. Intraductal Breast Papilloma. NCI Thesaurus. Code C3863.

A benign papillary neoplasm that arises anywhere in the ductal system of the breast. It is characterized by fibrovascular structures lined by benign epithelial and myoepithelial proliferations. Intraductal breast papillomas are classified as central, when they arise in large ducts, or peripheral, when they arise in the terminal ductal lobular units. 